\title{
Pseudotumoral Aspect of the Hydatic Cyst of the Kidney
}

\author{
Ismail Sarf*, Anas Meziane, Amine El Mejjad, Abdellatif Taha, \\ Rachid Aboutaeib, and Fathi Meziane \\ CHU IBN Rochd, Department of Urology, Casablanca, Morocco \\ E-mail: sarf.ismail@caramail.com
}

Received April 28, 2004; Accepted August 12, 2004; Published August 30, 2004

KEYWORDS: hydatid cyst, kidney, C.T scan, nephrectomy

DOMAIN: urology

\section{CASE REPORT}

A 58-year-old woman was examined for isolated continuous pains in the right flank since 3 months. She had no specific urinary problems. The physical exam she underwent did not detect any fullness in the right flank.

Serum biochemistry, haematology, and urine analysis were all normal. The ultrasound exam showed a heterogeneous mass of the right kidney. The computed tomography (CT) revealed a right renal mass measuring $4 \mathrm{~cm}$ out of $5 \mathrm{~cm}$, having a central necrosis, few calcifications on the wall, and a heterogeneous enhancement by contrast product (Fig. 1). The diagnosis of the right renal carcinoma was highly suspected, then a right nephrectomy was performed.

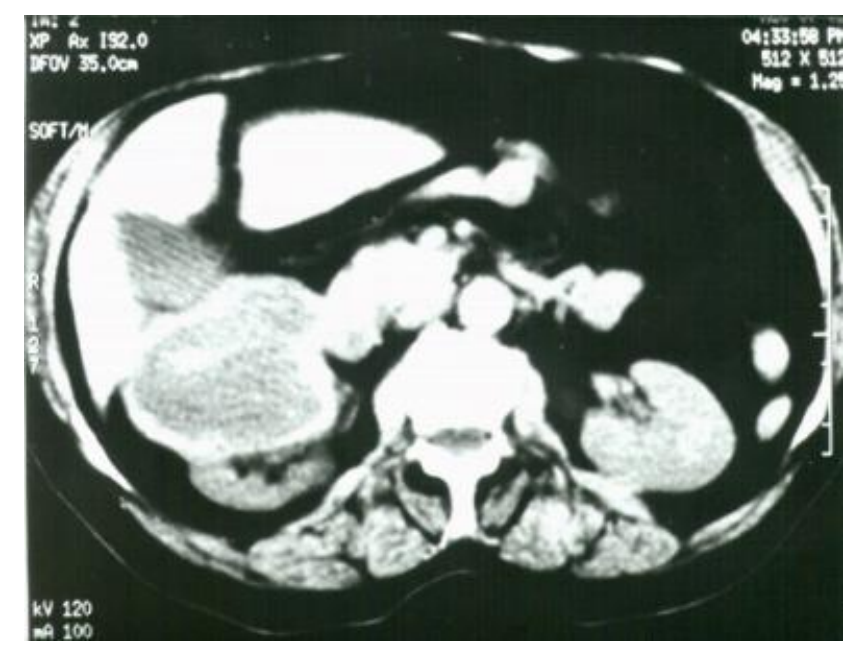

FIGURE 1. Computed tomography: Right renal mass $4 / 5 \mathrm{~cm}$, with central necrosis and heterogeneous enhancement by contrast product. 


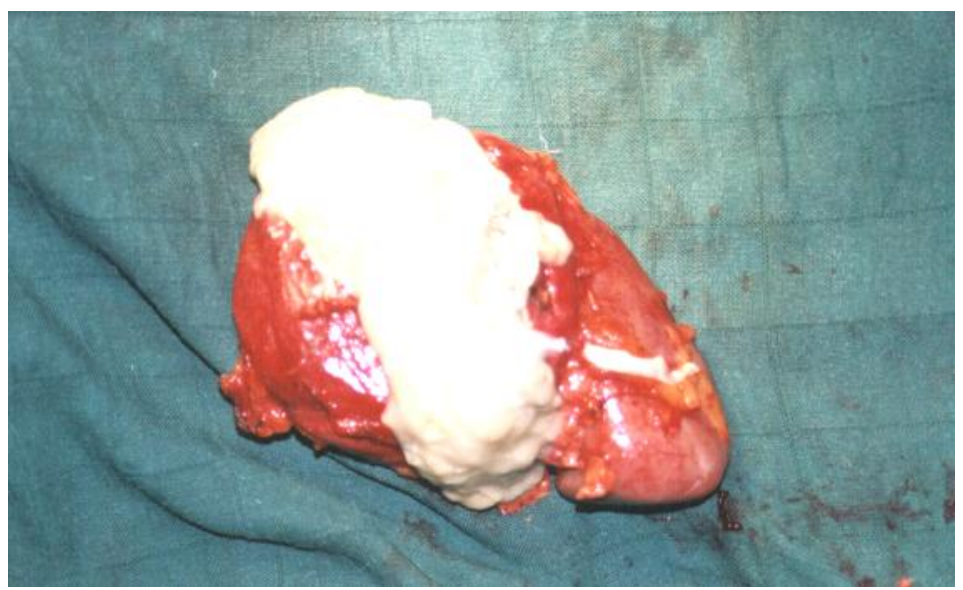

FIGURE 2. Macroscopic aspect: presence of whitish gelatinous infected substance at the opening of the kidney.

The macroscopic aspect of the kidney at its opening showed a whitish gelatinous infected substance with no evidence of malignant formation (Fig. 2).

The pathological examination showed a quasi-damaged kidney containing an atypical cyst full of hydatic membranes with thick wall.

\section{COMMENT}

Hydatic disease of the kidney is an unusual entity, representing 2-4\% of all cases of hydatic disease[1]. An accurate preoperative diagnosis of a hydatic cyst of the kidney assumes a high level of suspicion for the entity, since it usually mimics more familiar lesions of the kidney[2].

CT is assumed to be the most diagnostic of all laboratory and radiological investigations[3]. However, through this case, the authors think that the CT scan may be misleading and want to draw to the attention of all clinicians serving in the endemic area that hydatic disease should be considered in the differential diagnosis of solid occupying urinary tract lesions.

\section{REFERENCES}

1. $\quad$ Kirkland, K. (1966) Urological aspects of hydatic disease. Br. J. Urol. 39, 241.

2. $\quad$ Diamond, H.M., Lyon, E.S., and Hui, N.T. (1976) Echinococcal disease of the kidney. J. Urol. 115, 742.

3. Afsar, H., Yagci, F., and Meto, S. (1994) Hydatic disease of the kidney: evaluation and features of diagnostic procedures. J. Urol. 151, 567.

\section{This article should be referenced as follows:}

Sarf, I., Meziane, A., El Mejjad, A., Taha, A., Aboutaeib, R., and Meziane, F. (2004) Pseudotumoral aspect of the hydatic cyst of the kidney. TheScientificWorldJOURNAL 4, 758-759.

\section{Handling Editor:}

Anthony Atala, Principal Editor for Urology — a domain of TheScientificWorldJOURNAL. 


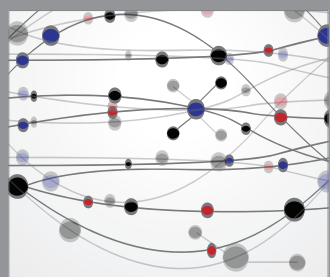

The Scientific World Journal
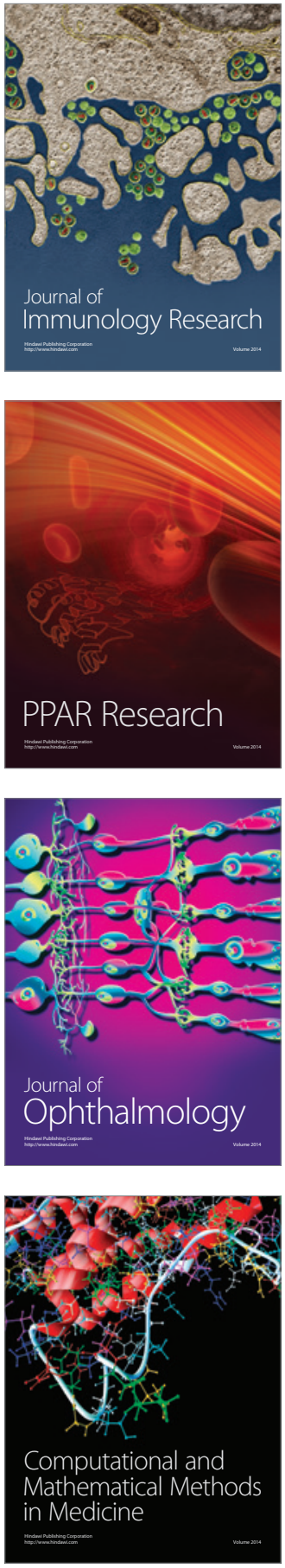

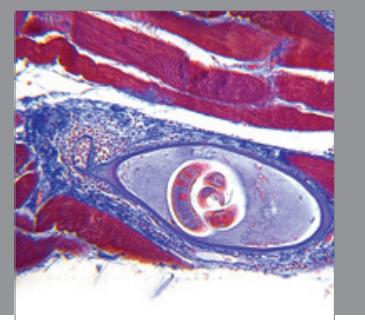

Gastroenterology

Research and Practice
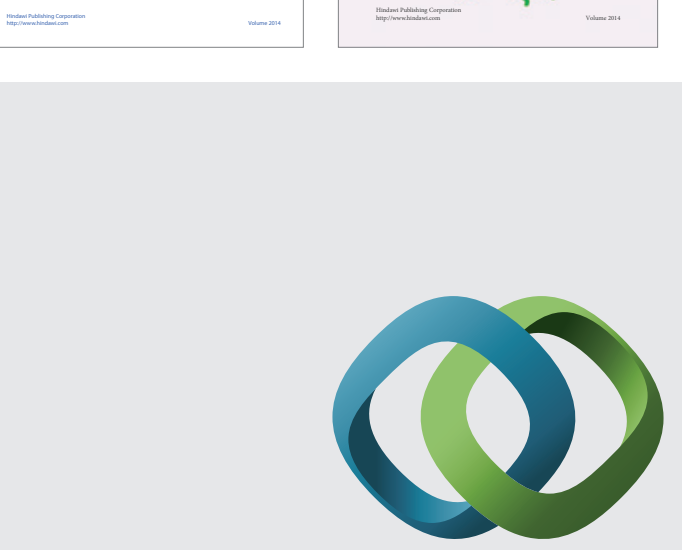

\section{Hindawi}

Submit your manuscripts at

http://www.hindawi.com
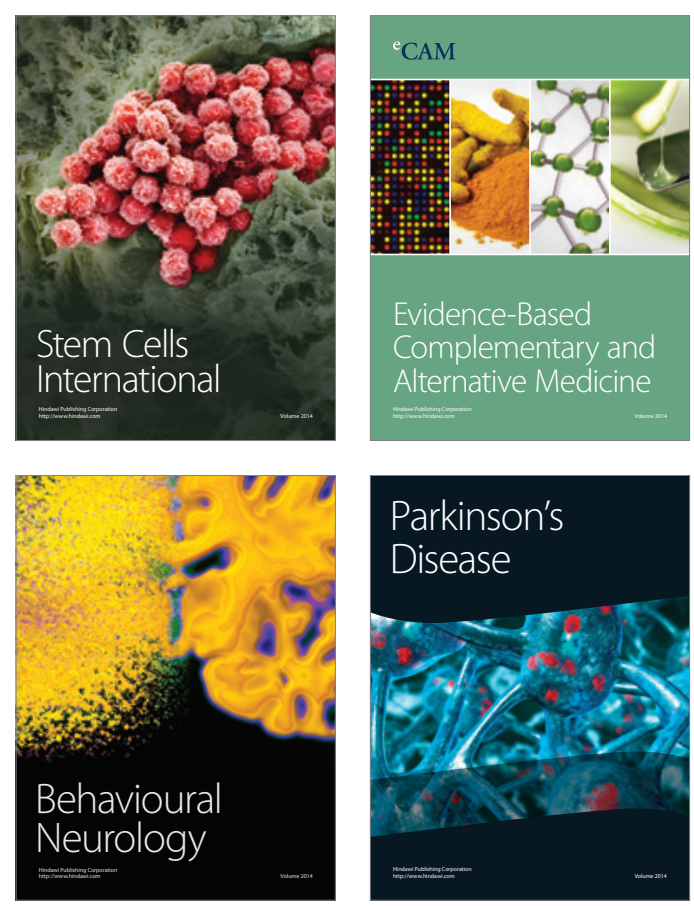

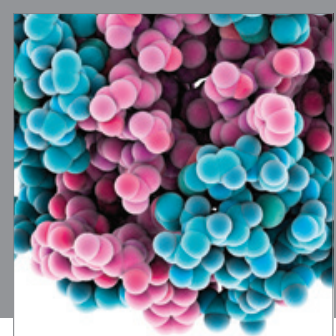

Journal of
Diabetes Research

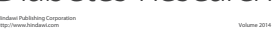

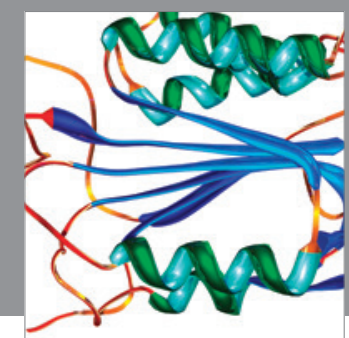

Disease Markers
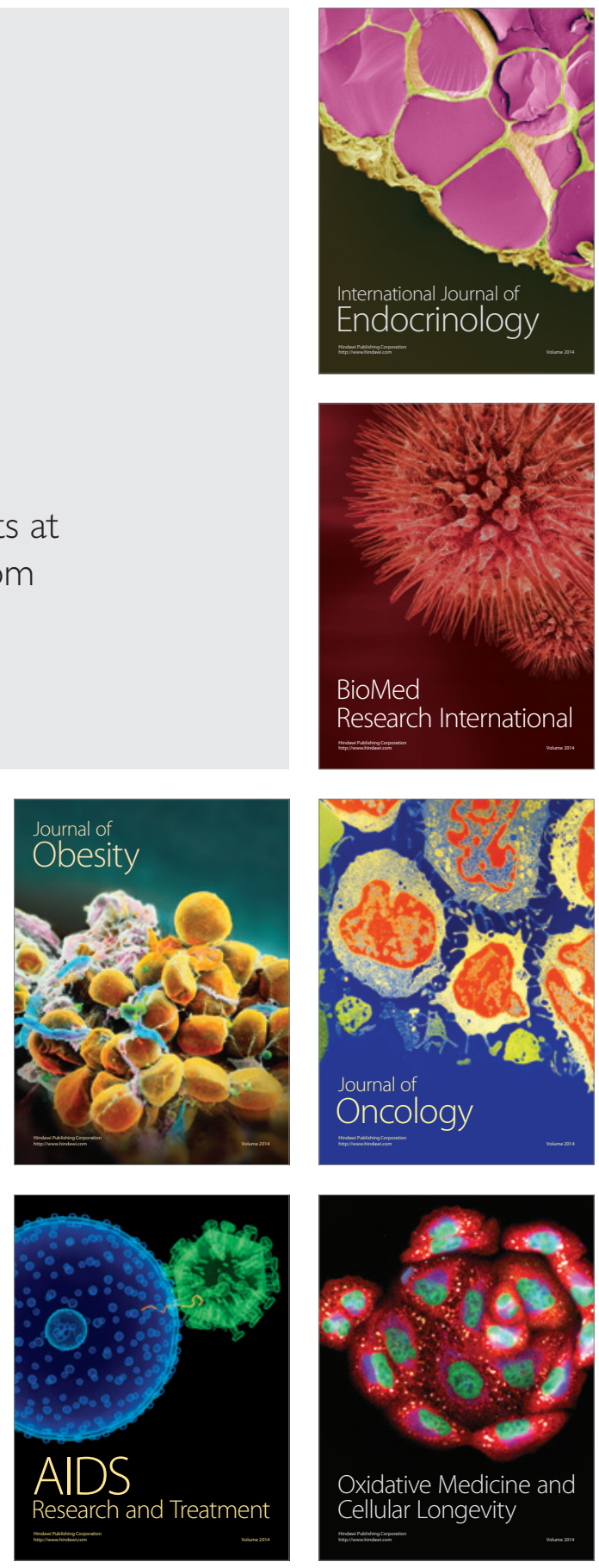